Int. J. Curr. Res. Med. Sci. (2016). 2(12): 8-13

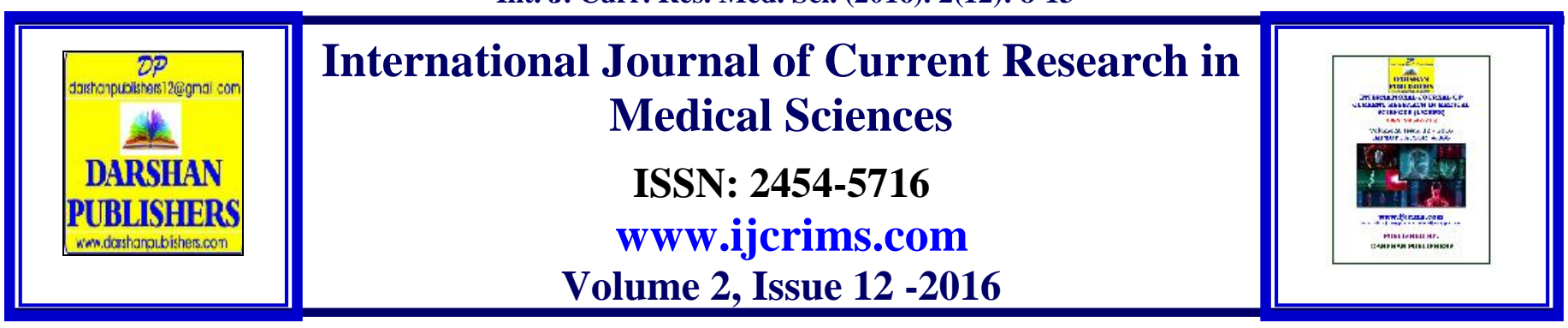

\title{
Pre-conceptional Maternal Diet and Fetal Sex pre-selection
}

\author{
Mahmoud Edessy*, Mahmoud I. El Rashedy, Khaled El Batal, Selim Ahmed, \\ Mahmoud Badawy, Abd Elraouf Oun, Ahmed Bendary
}

\author{
Department of Obstetrics \& Gynecology, Faculty of Medicine, Al Azhar University (Egypt) \\ *Corresponding author
}

\begin{abstract}
Background: Natural sex selection methods have been applied for several decades, but their use and effectiveness are still a matter of debate. Sex selection could be needed for personal, social, or cultural reason. In most cases the principal medical indication for sex selection is to avoid giving birth to children with a sex-linked genetic disorder.

Objective: this study was designed to assess the efficacy of a maternal diet as a method to improve the chances of conceiving a girl or boy.

Subject and Methods: total of 200 women were recruited in this study. Patients were grouped in to two groups according to the advised type of diet. Group 1: 100 women supplied by diet rich in Na \& K (if a male is desired) and group 2: 100 Women supplied by diet rich in calcium and magnesium (if female is desired). Compliance with diet was assessed through mineral analyses of blood.

Results: It was found that in group 1 (patients consumed diet rich in $\mathrm{Na}$ and $\mathrm{K}$ for male selection) the result was 76 male offspring, 16 female offspring, and 8 abortions with successful rate of male child of $76 \%$, while In group 2 (patients consumed diet rich in $\mathrm{Ca}$ and $\mathrm{Mg}$ for female selection) the result was 72 female offspring, 16 male offspring, and 12 abortions with successful rate of female child of $72 \%$.

Conclusion: maternal diet rich in $\mathrm{Na}, \mathrm{K}$ and $\mathrm{Ca}, \mathrm{Mg}$ are factors capable of increasing the probability of conceiving a baby upon the desire of the couples.
\end{abstract}

Keywords: Gender selection, maternal diet. Calcium, magnesium, sodium and potassium.

\section{Introduction}

In nature, there are about 105 male births for every 100 female births. It is recognized that the primary sex ratio is equal to one. However, certain cities have a somewhat variable sex ratio, showing at times a predominance of female sex and other times a predominance of male sex, there are many factors suggested to explain these differences (parents age, chemical factors, social factors, environmental factors, special factors such as wars.). (Stolkowski and Lorrain, 1980).
Gender preselection desire of the human species to control the gender of its progeny prior to conception has always existed. With sex selection, as with many issues of emotional appeal, political positions have predated careful reflection, and legislative initiatives have marched well in advance of strategic planning. Several factors enhance parents for baby gender selection range from family balancing to culturally imposed 
preference for boys to prevention of sex-linked hereditary diseases. The idea that maternal diet could influence the sex of the offspring has received considerable interest of many scientists and clinicians worldwide long time ago (Rosenfeld\& Roberts, 2004 and Noorlander et al., 2010).

Some of these clinical retrospective diet surveys carried out by (Lorrain, 1975 and Duc, 1977) confirmed that for couples with three or more girls and no boys, calcium and magnesium was decidedly dominant in the mother's diet, whereas the mothers of offspring predominantly male exhibited a sodium intake above average. A possible connection between the diet of patients and the sex of their descendants has been postulated several times (Chandraju et al. 2011).

\section{Subjects and Methods}

This study was initiated in January 2014 and terminated in October 2016 to test the hypothesis that the effect of maternal diet as a method to improve the chances of conceiving a girl or boy. Sex of the baby after birth was taken as the primary outcome measure for analysis. A total of 200 women were recruited in this study. Patients signed an informed consent explain the nature of the study after obtaining the ethical approval from ethical approval committee of Al Azhar Facullty of medicine. Detailed history, general, abdominal, local examination and full investigation were carried out to all participants. Patients were grouped in to two groups according to the advised type of diet as shown in table (1)

\section{Table (1): Advised Maternal Diet According To Its Mineral Content}

\section{Diet rich in Calcium}

Milk and dairy products

Bread made from white grain without salts and yeast

Grains like: almond hazelnut, sun flower seeds.

Salmon, sardine, oysters.

Vegetables especially lettuce, parsley, coriander, mallow, okra, carrot, garlic, spinach

Chickpeas, halva.

Butter without salt.

All fruit expect banana, peach, cherry, apricot, cooked tomatoes-

Honey, coffee, fish.

\section{Diet rich in Magnesium}

Bran bread.-almond, kazoo, peanuts, peanut butter without salt.

Soy beans potato in small amount.

Dairy products.

\section{Diet rich in Potassium}

Cornflakes, pretzels. Sugar, jelly, popcorn, margarine, jam.

Fruits like banana, apricot, grape fruit, watermelon.

Orange juice, pears, cherry, dried fruit.

Vegetables like green beans, cornflower, corn, peas, potato, sweet potato,tomatoes.

Chicken without its skin especially breast part.

Dried grains like lentis, white beans.

White bread.

Meat, fish.

Soups, coffee. 
Group 1: 100 women supplied by diet rich in $\mathrm{Na}$ $\& \mathrm{~K}$ (if a male is desired)

Group 2: 100 Women supplied by diet rich in calcium and magnesium (if female is desired)

\section{Study Procedure:}

\section{1- Diet Adjustment:}

Prior to treatment, a blood sample for each woman was analyzed for $\mathrm{Na}+\mathrm{K}+, \mathrm{Ca} 2+$ and $\mathrm{Mg} 2+$ concentrations. (normal sodium level is between 135 and $145(\mathrm{mEq} / \mathrm{L})$, normal potassium level is between 3.5-5.0 (mEq/L), normal calcium concentration is between $8.5-10.2 \mathrm{mg} / \mathrm{dL}$ normal magnesium level is between 1.7 to $2.2 \mathrm{mg} / \mathrm{dL}$ ). All serum analyses were performed using Willis methods for the determination of metals in blood serum by atomic absorption spectroscopy (Willis, 1960). These parameters were taken into account in a detailed personal diet advice, stipulating both allowed and excluded foods, aimed at increasing $\mathrm{Na}+\mathrm{K}+, \mathrm{Ca} 2+$ and $\mathrm{Mg} 2+$ concentrations in the blood to high normal level. The effect of the diet was checked after 5 weeks by a second serum analysis. If the blood concentrations showed insufficient effect after 5 weeks, diet and food supplement levels were adapted accordingly and blood values were checked again after 4 weeks.

\section{2- Pregnancy Follow Up:}

Pregnancy was detected chemically, and then recognized clinically using ultrasound, aborted cases were recorded, anti natal care was scheduled as usual for low risk pregnancies.

\section{3- Data Analysis:}

Data was tabulated and calculated using SPSS software version 22; Chi-square test was adopted according to (Sokal and Rohlf, 1994) p<0.05 was considered statistically significant.

\section{Results}

In this study, the effect of diet on sex selection was used and assessed.

In group (1): when we use diet rich in $\mathrm{Na}$ and $\mathrm{K}$ for male selection on 100 patients, the result was 76 male offspring, 16 female offspring, and 8 abortions with successful rate of male child of 76\%.In group (2): when we use diet rich in $\mathrm{Ca}$ and $\mathrm{Mg}$ for female selection on 100 participants, the result was 72 female offspring, 16 male offspring, and 12 abortions with successful rate of female child of $72 \%$.

Table (2): Descriptive statistics of age according to the outcome in the study groups

\begin{tabular}{|c|c|c|c|c|}
\hline & Age & $\begin{array}{l}\text { Na \& K group } \\
\quad(\mathrm{N}=100)\end{array}$ & $\begin{array}{l}\text { Ca \& Mg group } \\
\qquad(\mathrm{N}=100)\end{array}$ & p. value \\
\hline \multirow{4}{*}{ Abortion } & A & 8 & 0 & $0.01 *$ \\
\hline & B & 0 & 12 & $0.01 *$ \\
\hline & $\mathrm{C}$ & 0 & 0 & N.A \\
\hline & Total & 8 & 12 & $0.04 *$ \\
\hline \multirow{4}{*}{ Male } & A & 34 & 4 & $0.01 *$ \\
\hline & B & 31 & 12 & $0.01 *$ \\
\hline & $\mathrm{C}$ & 11 & 0 & $0.01 *$ \\
\hline & Total & 76 & 16 & $0.01 *$ \\
\hline \multirow{4}{*}{ Female } & A & 8 & 32 & $0.01 *$ \\
\hline & $\mathrm{B}$ & 8 & 16 & $0.02 *$ \\
\hline & $\mathrm{C}$ & 0 & 24 & $0.01 *$ \\
\hline & Total & 16 & 72 & $0.01 *$ \\
\hline
\end{tabular}

$\{\mathrm{A}=$ age from $20-25, \mathrm{~B}=$ age from $25-30, \mathrm{C}=$ age from $30-35\}$ 
Int. J. Curr. Res. Med. Sci. (2016). 2(12): 8-13

Table (3): Descriptive statistics of $\mathrm{Na} \& \mathrm{~K}$ pre-program according to the outcome

\begin{tabular}{|c|c|c|c|c|c|c|c|c|}
\hline & & Outcome & $\mathrm{N}$ & Min & $\operatorname{Max}$ & Mean & S.D & P. value \\
\hline \multirow{6}{*}{ 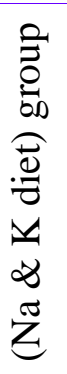 } & \multirow{3}{*}{$\mathrm{Na}$} & Abortion & 8 & 137.0 & 137.0 & 137.0 & 0.0 & \multirow{3}{*}{0.3} \\
\hline & & Female & 16 & 133.9 & 144.0 & 139.4 & 3.7 & \\
\hline & & Male & 76 & 129.0 & 149.0 & 137.9 & 4.04 & \\
\hline & \multirow{3}{*}{$\mathrm{K}$} & Abortion & 8 & 4.1 & 4.1 & 4.1 & 0.0 & \multirow{3}{*}{$0.02 *$} \\
\hline & & Female & 16 & 3.3 & 4.8 & 4.05 & 0.6 & \\
\hline & & Male & 76 & 3.0 & 4.4 & 3.8 & 0.4 & \\
\hline \multirow{6}{*}{ 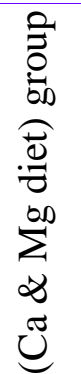 } & \multirow{3}{*}{$\mathrm{Na}$} & Abortion & 12 & 141.0 & 147.0 & 143.0 & 2.9 & \multirow{3}{*}{$0.01 *$} \\
\hline & & Female & 72 & 137.0 & 154.0 & 144.7 & 4.6 & \\
\hline & & Male & 16 & 139.8 & 159.0 & 148.7 & 7.2 & \\
\hline & \multirow{3}{*}{$\mathrm{K}$} & Abortion & 12 & 4.1 & 5.3 & 4.5 & 0.6 & \multirow{3}{*}{0.4} \\
\hline & & Female & 72 & 3.8 & 5.1 & 4.5 & 0.42 & \\
\hline & & Male & 16 & 4.1 & 5.1 & 4.7 & 0.37 & \\
\hline
\end{tabular}

In ( $\mathrm{Na} \& \mathrm{~K}$ diet) group, there was no statistically significant difference between participant outcomes in $\mathrm{Na}$, while in $\mathrm{K}$ we found statistically significant difference between participant outcomes with $(\mathrm{P}$-value<0.02), While in $(\mathrm{Ca} \&$
$\mathrm{Mg}$ diet) group we find statistically significant difference between patient outcomes with (Pvalue $<0.01)$ in $\mathrm{Na}$, but no statistically significant difference between patient outcomes in K. Table (3).

Table (4): Mean pre-and postconceptional Serum concentrations of the studied minerals

\begin{tabular}{|c|c|c|c|c|}
\hline \multirow{2}{*}{ Group } & \multicolumn{2}{|c|}{ Group 1 (N=100) } & \multicolumn{2}{c|}{ Group 2 (N= 100) } \\
\hline Serum Minerals & $\begin{array}{c}\text { Na } \\
(\mathbf{M m o l} / \mathbf{L})\end{array}$ & K (Mmol/L) & Ca (mg/dl) & Mg (mg/dl) \\
\hline Preconceptional & 138.16 & 3.83 & 8.50 & 1.96 \\
\hline Postconceptional & 148.48 & 5.01 & 10.02 & 2.36 \\
\hline \% of Change & $7.46 \%$ & $30.80 \%$ & $17.88 \%$ & $20.40 \%$ \\
\hline
\end{tabular}

\section{Discussion}

The current study investigated the efficacy of a combined diet rich in ( $\mathrm{Na}, \mathrm{K}, \mathrm{Ca}$ and $\mathrm{Mg}$ ), as a sex pre-selection factors. The effect of diet rich in minerals resulted in $72 \%$ for females and $76 \%$ for males, which in agreement with the results of (Stolkowski and Choukroun,1981) who reported the effect of $\mathrm{Na}, \mathrm{K}, \mathrm{Ca}$, and $\mathrm{Mg}$ on human offspring the result was $80 \%$ males. Stolkowski and Lorrain (1980) Papa et al. (1983) Devaure et al. (1989) and Jeambrun (1989) have studied women who adhered to a pre-conception diet specific in its amounts of calcium, magnesium, sodium and potassium. Between $75 \%$ and $80 \%$ of the mothers were successful in delivering a baby of the desired sex. Also, (Vahidi and Sheikhha, 2007) give ( $\mathrm{Na}, \mathrm{K}, \mathrm{Ca}$ and $\mathrm{Mg}$ ) supplement to the rats. The results showed $68 \%$ females in calcium and magnesium group and $70 \%$ males in sodium and potassium group. More recently our work was supported by (Chandraju et al., 2011) who study on the effect of $\mathrm{Ca}$ and $\mathrm{Mg}$ on rats fed with $(\mathrm{Ca}$, $\mathrm{Mg}$ ) food yields maximum numbers of female offspring, while rats fed with normal food yields lowest numbers of male offspring. 
In the current study referring to mean concentration of serum $\mathrm{Na}, \mathrm{K}, \mathrm{Ca}$ and $\mathrm{Mg}$ preconceptionally it was found that diet rich in such minerals elevate their concentration postconceptionally and these elevations were $(7.46 \%, 30.80 \%, 17.88 \% \& 20.40 \%)$ for $\mathrm{Na}, \mathrm{K}, \mathrm{Ca}$ and $\mathrm{Mg}$ respectively.

The idea that maternal diet could influence the sex of the offspring has received considerable interest of many scientists and clinicians worldwide long time ago. Some of these clinical retrospective diet surveys confirmed that for couples with three or more girls and no boys, calcium and magnesium, was decidedly dominant in the mother's diet, whereas the mothers of offspring predominantly male exhibited a sodium intake above average. A possible connection between the diet of patients and the sex of their descendants has been postulated several times. In UK a group of scientists surveyed maternal dietary in (740) women and has confirmed a predominance of sodium and potassium in the pre-conceptional mineral intake of mothers who bore boys (Mathews; 2008).

The balance between sodium and potassium versus calcium and magnesium could change the receptors of the oocyte wall to favor the attraction of either a male or female sperm. When there is a high sodium and potassium intake, and a low calcium and magnesium in the female's diet, the oocyte wall will change to attract the (y-sperm). While, more calcium and magnesium in the blood and a low sodium and potassium will attract the (x-sperm). The connection between mineral intake and sex ratio of the offspring was first observed in the rat during long-term experiments. The result was $68 \%$ in calcium and magnesium group and $70 \%$ in sodium and potassium group (Vahidiv and Sheikhha, 2007).

In human the mechanisms by which diet influences sex remain unknown. Noorlander et al., 2010 postulated that the diet possibly induces ionic and/or hormonal changes that interact either through the cervical mucus with spermatozoa or at the oocyte level. Finally, differential survival of male and female embryos cannot be ruled out.

\section{Conclusions}

This study concluded that the diet method (relative excess of sodium and potassium ions) would favor the birth of males, while relative excess of $\mathrm{Ca}$ and $\mathrm{Mg}$ ions in the diet would favour the birth of female. So by altering diet to include and exclude certain food, the condition in the reproductive tract will be directly affected; increasing the number of a particular sex.

\section{References}

1. Chandraju, S.; Ashraf Beirami and Chidan Kumar C.S. Impact of Calcium and Magnesium Ions in Identification of Baby Gender in High-Sugar Hamsters. J. Pharm. Sci. \& Res. Vol.3 (12), 2011, 1619-1624

2. Devaure, N., Dabadie, H., Paccalin, J., 1989. Influence des apportsnutritionnelsdans le de'terminisme du sexe. Diet. Med. 2, 155163.

3. Duc, M., 1977. De l'influence des apportnutritionnelsen ions $\mathrm{K}+, \mathrm{Na}+, \mathrm{Ca} 2+$, Mg2+ sur la sex-ratio chez l'homme. Ph.D. thesis, Universite' de Paris-Val-de-Marne, $56 \mathrm{p}$.

4. Jeambrun, P., 1989 . Escolha pre'concepcionaldosexopormeio de dieta. Servir 38, 179-182.

5. Lorrain, J., 1975. Pre-conceptional sex selection. Int. J. Gynecol. Obstet. 13, 127130.

6. Mathews, F., Johnson, P.J., Neil, A., 2008. You are what your mother eats: evidence for maternal preconception diet influencing foetal sex in humans. Proc. R. Soc. B: Biol. Sci. 275, 1661-1668.

7. Noorlander AM, Geraedts JPM and Melissen JBM. 2010. Female gender preselection by maternal diet in combination with timing of sexual intercourse -a prospective study. Reproductive BioMedicine Online 21, 794- 802.

8. Papa, F., Henrion, R., Breart, G., 1983. Se'lection pre'-conceptionelle du sexe par la me'thodeionique. J. Gynecol. Obstet. Biol. Reprod. (Paris) 12, 415-422. 
Int. J. Curr. Res. Med. Sci. (2016). 2(12): 8-13

9. Rosenfeld C.S., Roberts R. M, 2004, Maternal Diet and Other Factors Affecting Offspring Sex Ratio: A Review. Biology of Reproduction, 71, 1063-1070.

10. Sokal, R.R., Rohlf, F.J., 1994. Biometry: The Principles and Practice of Statistics in Biological Research, third edition. Freeman, New York, ISBN: 0-7167-2411-1.

11. Stolkowski J and choukroun J. 1981. preconception selection of sex in man. Israel $\mathbf{J}$ of medical science. 17:1061-1067.
12. Stolkowski J and Lorrain J. 1980. preconceptional selection of fetal sex. Int $\mathbf{J}$ gynaecol obstet. 18:440-443.

13. Vahidi, A.R. and Sheikhha, M.H. 2007.Comparing the Effects of Sodium and Potassium Diet with Calcium and Magnesium Diet on Sex Ratio of Rats' Offspring Pakistan Journal of Nutrition 6 (1): 44-48.

\begin{tabular}{|c|l|}
\hline \multicolumn{2}{|c|}{ Access this Article in Online } \\
\hline Q & Website: \\
& www.ijcrims.com \\
\cline { 2 - 3 } Quick Response Code & \\
\hline
\end{tabular}

How to cite this article:

Mahmoud Edessy, Mahmoud I. El Rashedy, Khaled El Batal, Selim Ahmed, Mahmoud Badawy, Abd Elraouf Oun, Ahmed Bendary. (2016). Pre-conceptional Maternal Diet and Fetal Sex pre-selection. Int. J. Curr. Res. Med. Sci. 2(12): 8-13.

DOI: http://dx.doi.org/10.22192/ijcrms.2016.02.12.002 